\title{
Editor's Introduction: Theory, Change and Biology
}

\author{
Lawrence T. Nichols ${ }^{1}$
}

Accepted: 16 November 2020 / Published online: 23 November 2020

(C) Springer Science+Business Media, LLC, part of Springer Nature 2020

In this issue we present a set of articles that range widely over concepts and theories, both old and new, with important implications for future sociological thought and research practice. Three papers explore the possibility of revitalizing older approaches in sociology, while a fourth traces the use, over time, of particular vocabularies. Some articles also share a focus on policy, including poverty relief programs, natural resource management and the operation of a major sociological journal. There is critique, but the emphasis throughout is on creative alternatives, on building up the field.

Elizabeth Seale is concerned with the issue of how sociologists doing research on impoverished groups might incorporate the idea of culture in their theoretical frameworks and methodologies. In the mid-twentieth century, the perspective of a "culture of poverty," mostly closely associated with the writings of anthropologist Oscar Lewis, tried to explain the intergenerational persistence of poverty by characterizing an alleged distinctive "culture" as a fundamental cause. This view, however, was widely discredited as a "victim blaming" interpretation that tended to stigmatize vulnerable populations, often on the basis of race and ethnicity. More recently, sociologists have taken a largely "structural" view of poverty as the result of disparities of power. As in earlier critical perspectives such as Marxism, this has involved a tendency to see culture as derivative and often little more than a rationale for ongoing oppression. In Seale's view, sociologists need to find new, creative ways of reintroducing understandings of culture in poverty studies. The author therefore suggests approaching culture in terms of "the ways in which poverty is experienced and constructed," with an emphasis also on social relations, rather than on individuals.

Raymond Lee believes the time is ripe for the revitalization of the subfield of collective behavior. In its early days, this subfield dealt largely with issues such as the psychology of crowds, the debate over the existence of a "group mind," and the role of masses in processes of change. Symbolic interactionist theorists such as Herbert Blumer also spoke of societies as forms of collective behavior, but this framing did not acquire a large following. Lee sees a renewed potential in the emergence of research on networks and also in the spread of "digitized collectivities." There is new thinking on

Lawrence T. Nichols

ltnichols@retiree.wvu.edu

1 West Virginia University, Morgantown, WV, USA 
multitudes, swarms and publics, sometimes in connection with the issue of mass surveillance, all of which provides new opportunities for sociologists.

Mitsuhiro Tada addresses the issue of the relation between individual freedom and social order through the lens of the social systems theory of Niklas Luhmann. The author is especially interested in Luhmann's discussion of how "sociological enlightenment" can contribute to ongoing human evolution. Tada challenges the idea, promoted by such prominent thinkers as Emile Durkheim, that social evolution requires a "controlling entity" such as the modern nation-state. On the contrary, in the author's view, it is increasing individual freedom within a social order that is the key to the future progress of the human species. "Sociological enlightenment" thus brackets the taken-for-granted reality of any particular social order, and it values the amplification of deviations that might lead to enlarged and more diversified possibilities.

Jonathan Turner, Russell K. Schutt and Matcheri S. Keshavan contribute the second part of their proposal for developing an evolutionary sociology. As the authors note, evolutionary perspectives were prevalent in the field during the nineteenth century and the first two decades of the twentieth, after which they largely disappeared. Now, however, the authors believe that there is an opportunity for sociology to develop its own evolutionary outlook in a way that would avoid mistakes of the past while also linking with contemporary intellectual movements in psychology, biology and economics. Their vision is that of a progressive and future-oriented approach that might appeal to a wide range of sociologists and connect with intellectually exciting research in epigenetics and social neuroscience. Such an approach might provide valuable insights into such sociological subfields as gender, inequality, race and ethnicity, the sociology of the body and the sociology of emotions - all with implications for building a better social order.

Pavel Sorokin asks whether sociology can provide a positive, optimistic vision of the future despite the range of contemporary crises such as the current pandemic. The author draws especially on the World Society Theory of John Meyer and its concept of "Otherhood." The promise of Meyer's model, Sorokin believes, can be more fully realized if it were combined with another global perspective, namely, Pitirim A. Sorokin's "Integralism." This theory might be described as "dialectical," but in the sense of complementarity among opposites (as in such ancient traditions as Confucianism), more than in terms of their mutual conflicts (as in the better known HegelianMarxian approach). A key component within the grand scheme of Integralism is altruism, which Pitirim Sorokin, following such thinkers as Pyotr Kropotkin, considered a fundamental cause of human survival and historical evolution. Combining World Society Theory with Integralism, Pavel Sorokin concludes, might provide a means for the social sciences to play a practical role in future global development.

Dmitri Shalin advocates the development of a more fully "embodied" sociology. In support of this proposal, the author notes how two earlier thinkers, Norbert Elias and George Herbert Mead, whose careers overlapped, took initial steps in this direction. Both presented accounts of a socio-psychological reality that was "dialectical and process-oriented," with a recognition of the interplay between the rational, the emotional and the physical. In Shalin's view, these models are closely related to recent and current developments in neuroscience and behavioral epigenetics, all of which might contribute to a new program of embodied sociology.

Norbert Wiley provides a first-person account of an effort by himself and Norman $\mathrm{K}$. Denzin to promote reforms in the operation of the major journal of the American 
Sociological Association, the American Sociological Review. This took the form of an appeal to the Council of ASA during which Wiley shared evidence of widespread dissatisfaction with the journal among the association's members. Denzin and Wiley hoped in particular to broaden opportunities for the presentation of symbolic interactionist work, but they had other concerns as well, including gender representation among the journal's editors. In the end, the reformers could claim at least partial victory in the form of responsiveness to some of their concerns and the appointment of the first woman editor of ASR, Rita Simon. Wiley's engaging narrative, which is conceptual as well as historical, remains relevant, for symbolic interaction might be even more marginal today than it was in 1976, when influential figures such as Herbert Blumer were still active. For the intervening decades have witnessed the rise of quantitative analysis and also of the conflict perspective, both of which include proponents strongly opposed to symbolic interactionism, either for its alleged imprecision or for its lack of an account of power and inequality.

R. Patrick Bixler seeks to extend Michael Burawoy's idea of “organic public sociology" into the area of community-based natural resources management, for the dual purpose of improving livelihoods and planetary sustainability. Bixler's call for rural sociologists to "go public" is actually in accord with longstanding tradition in that field, at least since the 1920s when sociologists such as Carle C. Zimmerman worked closely with Agricultural Experiment Stations. Many sociologists today are not aware that a number of "land-grant" universities, operating under a mandate of public service in their respective states, had separate departments of rural sociology, often located apart from sociology departments in their colleges of Arts and Sciences. This was the case, for example, at the universities of Minnesota and Wisconsin, as well as at Penn State and Cornell. Bixler frames his appeal in terms of citizen participation, empowerment and the co-production of knowledge.

Oxana Mikhaylova and Roman Abramov, finally, provide a sophisticated bibliometric analysis of the appearance of the terms "ideology" and "discourse" in more than fifteen thousand publications by American and British scholars during the period 1966 to 2015. The authors present data not only on the frequency of each of these terms, but also on their relative popularity and their prevalence in various disciplines, including sociology, in particular journals and at particular universities. All of this, of course, fluctuates over time. Thus, the term "ideology" was quite prevalent in the American Sociological Review during the decade 1976 to 1985, while "discourse" was prominently featured in the American Journal of Sociology from 1986 to 1995 - findings that illumine ways of thinking popular at those times. More recently, the term "ideology" has declined in sociology relative to "discourse." The authors believe, however, that recent events around the world might stimulate fresh thinking about ideology, so that it might again become a basic component of sociological vocabulary and framing practices.

Publisher's Note Springer Nature remains neutral with regard to jurisdictional claims in published maps and institutional affiliations. 